\title{
An Exploratory Study of Responsiveness of Chinese Third-Party Logistics Providers in The Context of Cross-Border Electronic Commence:A Global Value Chain Perspective Yangyan Shi ${ }^{*}$, Chunxiao Xie \\ Shanxi University, China \\ *Corresponding author: Yangyan Shi, Doctor, yshi@sxu.edu.cn
}

\begin{abstract}
The cross-border electronic commerce (e-commerce) has become a major stream in the context of globalization. Third-party providers (3PLs) play a crucial role in linking with international business. This research seeks to explore the responsiveness of Chinese 3PL in the context of cross-border ecommerce through researching on influential factors, such as the level of specialization, the degree of goal-oriented congruence of partners, and cultural differences. The proposed contribution for this research will help Chinese 3PL providers improve their responsive performance in the context of cross-border e-commerce, from the perspective of the Global Value Chain. Also, it helps the 3PL providers identify the potential of value-added creation for both 3PL customers and themselves in the context of cross-border e-commerce.
\end{abstract}

Key words: responsiveness; third-party logistics provider; cross-border e-commerce; global value Chain; specialization level; goal-oriented congruence; cultural differences

\section{Introduction}

With the development of global economic integration, a market has a significant power to influence on the resource allocation. The international business shows the way of international value chains. The deep development of the global economic integration requires that countries develop a possible solution to solve the obstacles of international business. Many countries have announced a series of collaborative agreements in the circumstances, such as Trans-Pacific Partnership (TPP) and 'One Belt and One Road i,. In the formation process of the global value chain, the 3PL providers is also preferred by cross-border ecommerce firms.

The global value chain dominates the deep change of global trade pattern. It is widely studied in the academic publications of the global industry, and its framework has been adopted by many international organizations that focus on economic development. The global value chain refers to gradually replace product division with the division of production process, that is, the production process is divided into different parts and different economies engaged in different part(Gary Gereffi et al.,2012, ${ }^{1}$ ). It aims to integrate every piece of fragmentation of production in each country in order to aggregate those resources as one'organic entity'( $\mathrm{Pol}$ Antràs et al.,2013, ${ }^{2}$ ). In the recent years, the scope and field of international division of labor continues expand, forming a 'global value chain specialization' system (Timmer et. al,2014, ${ }^{3}$ ).

\footnotetext{
i 'One Belt and One Road' refers to the 'Silk Road Economic Belt' and the'21st Century Maritime Silk Road'.It's not a mechanism,but is concept and initiate of cooperative development.It'll fully rely on existing cooperation platform between China and the relevant countries.
} 
The development of global value chain can improve the performance of 3PL providers. The 3PL can greatly optimize the supply chain in the integration of information and resources(Jothimani,2014, ${ }^{4}$ ).Meanwhile, it has become a primary choice for cross-border ecommerce supplier with its professionalism and advancement in the field of logistics.

With forming the global value chain, cross-border e-commerce with a new business model quickly meets the increased demand of international trade.The development of cross-border ecommerce has been focused by many organizations since this business mode can reduce the intermediates from the sourcing to reaching customers. Cross-border e-commerce also facilitates the flows of information, labor, and materials, and provides an interactive multilevel and multi-angle business services for the global manufacturers and traders among different countries (Martin et al.,2014, ${ }^{5}$ ).Meanwhile, it can break through the limitation in the material, time, space of traditional trade activities, and promote the further development of international trade(Gomez-Herrera et al.,2014, ${ }^{6}$ ). Moreover, the cross-border sellers and buyers need to deeply rely on the excellent logistics service offered by their logistics providers(Wee Kwan Tan et al.,2014, ${ }^{7}$ ). The activities of international business need to collaborate with third-party logistics providers (3PL providers) in the overseas' markets in order to quickly respond to the changing customers' requirements (Rabinovich et al., $\left.2007,{ }^{8}\right)$.This can help companies reduce costs and creating a competitive advantage.The cross-border e-commerce requires to increase the responsiveness of logistics service, such as a short lead time from placing an order to final delivery. However, the implementation of 'quick response' strategy by 3PL providers have faced some challenges in the context of international trading business, in terms of specialization level in the logistics field, the degree of goal-oriented congruence of partners and cultural differences. For example, the professional level of the 3PL providers in the logistics filed directly affect the minimum time for each part of logistics, and it is the most obvious factor affecting the logistics service; the degree of goal-oriented congruence of partners and cultural differences will affect the trust and cooperation between partners, and then affect the realization of quick response strategy.

The majority of current researches focuses on 3PL providers examining their competitive advantages and the optimize 3PL functions. Terzi proves cross-border e-commerce would reduce trade barriers and promote trade growth after comparison and analysis of the data provided by OECD (Terzi, 2011, ${ }^{9}$ ). Research on the global value chain mainly focused on its impact on enterprises, that is, how does the enterprise achieve industrial upgrading in the global value chain? This paper mainly propose three factors influencing the responsiveness of 3PL providers in the context of border-cross e-commerce from the global value chain perspective, which is specialization level in the logistics field, the degree of goal-oriented congruence of partners, and cultural differences. This paper also lays the foundation for further research and provide direction. The proposed contribution for this research will help Chinese 3PL providers improve their responsive performance. It also helps the 3PL providers identify the potential of value-added creation for both 3PL customers and themselves in the context of cross-border e-commerce. 


\section{Research hypothesis and conceptual model}

\subsection{Research hypothesis}

Analyzing the results of some scholars, the paper studies from the perspective of the globalvalue chain, and propose three factors influencing the responsiveness of 3PL providers in the context of border-cross e-commerce, which is specialization level in the logistics field, the degree of goal-oriented congruence of partners and cultural differences. According to the inductive analysis, the following three hypothesis are put forward:

Specialization level in the logistics field determines the level of a logistics service(Bosire et $\left.a l ., 2013,{ }^{10}\right)$. They argue that high service level requires firms to complete business efficiently, such as a short lead time from placing an order to final delivery. Therefore, higher specialization level can lead to quicker responsiveness of the logistics enterprise, while lower specialization level will lead to various problems in all aspects of logistics service. Thus, it is predicted:

Hypothesis 1: Specialization level in the logistics field has a positive correlation with the responsiveness of the third-party logistics providers.

Stephan Sluis argues that supply chain partners will trust each other if there is a higher congruence of goal-oriented, which are seen as the foundation of cooperation between partners (Stephan Sluis et al.,2016, ${ }^{11}$ ). Generally, supply chain partners are not afraid of sharing information if their partner is based on trust (Stephan Sluis et al., 2016, ${ }^{11}$ ). The 3PL providers can identify the requirement of clients accurately, and quickly respond to the requirements of customers. Thus, it is predicted:

Hypothesis 2: The degree of goal-oriented congruence of SC partners has a positive correlation with the responsiveness of the third-party logistics providers.

With the formation of the global value chain, the 3PL providers are putting more and more attention to cross-border e-commerce. Cultural differences will invite unnecessary issues inside or outside an enterprise. The greater differences between countries, the lower trust level between the two parties; the greater differences among foreign employees inside a company, the lower efficiency of the cooperation among employees(Raue et al.,2013, ${ }^{12}$ ). Therefore, cultural differences affects the level of commitment in quick response strategy.

Hypothesis 3: Cultural differences has a negative correlation with the responsiveness of the third-party logistics providers.

\subsection{Conceptual model}

For the three factors influencing the responsiveness of the 3PL providers, their observable variables are shown in Table 1. 
Table 1 - Measurable index

\begin{tabular}{|c|c|}
\hline latent variables & observable variables \\
\hline $\begin{array}{l}\text { specialization level in the } \\
\text { logistics field }\end{array}$ & $\begin{array}{l}\text { 1.logistics elemental capacity } \\
\text { 2.logistics operation capability } \\
\text { 3.customized logistics }\end{array}$ \\
\hline cultural differences & $\begin{array}{c}\text { 4.management differences } \\
\text { 5.value standard } \\
\text { 6.way of thinking } \\
\end{array}$ \\
\hline $\begin{array}{l}\text { the degree of goal-oriented } \\
\text { congruence of SC partners }\end{array}$ & $\begin{array}{l}\text { 7.collaboration between SC parties } \\
\text { 8.information sharing degree } \\
\text { 9.gain-sharing consciousness }\end{array}$ \\
\hline $\begin{array}{l}\text { the responsiveness of 3PL } \\
\text { providers }\end{array}$ & $\begin{array}{c}\text { 10.service evaluation system } \\
\text { 11.customer relationship management } \\
\text { 12.value-added services }\end{array}$ \\
\hline
\end{tabular}

According to the above three hypothesis and corresponding observable variables,we build a conceptual model for the responsiveness of the 3PL providers, as shown in Fig. 1.

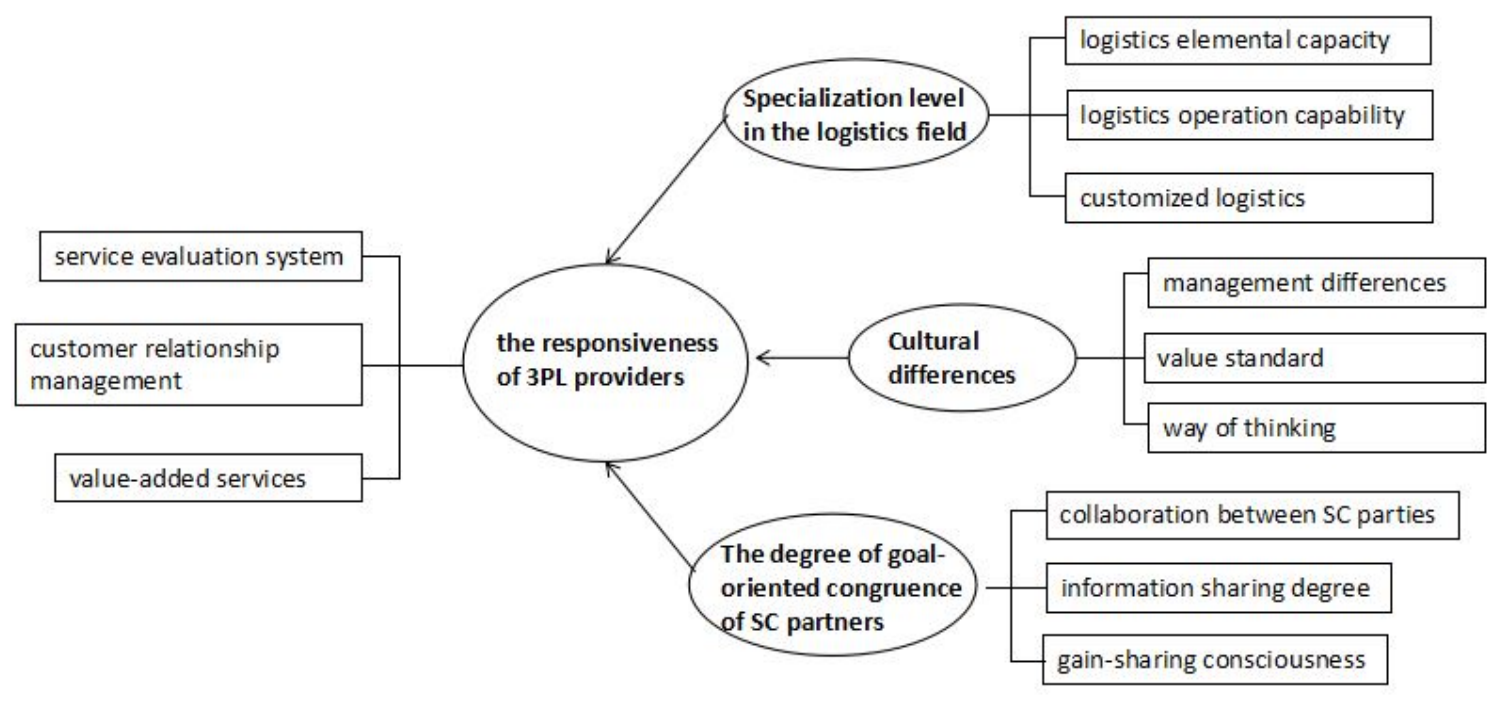

Fig. 1 - Conceptual model for he responsiveness of the 3PL providers

\section{Conclusion and Future research}

Cross-border e-commerce is the main mode of 'internet plus and foreign trade'( Luo, Kevin,2016, ${ }^{13}$ ). It has become a new driving force of Chinese foreign trade. Based on the gap of current research, this paper proposes a conceptual model regarding the responsiveness of the third-parties logistics providers in the context of the cross-border e-commerce, from the perspective of the global value chain. The study mainly includes three factors influencing the responsiveness of 3PL providers, which is specialization level in the logistics field, the degree of goal-oriented congruence of partners, and cultural differences.

First of all, the specialization level in the logistics field is a core competitiveness of a logistics provider. Professional logistics system could reduce costs, cut down the loss of each logistics 
part, provide customers with satisfactory service, and quickly respond to the requirements of customers(Bosire et al.,2013, ${ }^{10}$ ).Moreover, high degree of goal-oriented congruence of supply chain partners enhances the trust between them and identify the requirement of clients accurately(Stephan Sluis et al., 2016, ${ }^{11}$ ). Finally, due to the characteristic of the cross-border e-commerce, cultural differences inevitably exist in the 3PL providers and supply chain parties(Raue et al.,2013, ${ }^{12}$ ). Such cultural differences often result in unnecessary problems, so that the efficiency of cooperation between staffs will be low. The paper also supposes the correlation between the responsiveness of the 3PL providers and these three factors, and provide direction for future research.

Analyzing from the perspective of the global value chain, this study proposes that three factors influencing the responsiveness of 3PL providers, firms can properly adjust the unreasonable place, accurately identify the changing requirement of clients, and quickly respond to their customers. Furthermore, it also helps the 3PL providers identify the potential of value-added creation for both 3PL customers and themselves in the context of cross-border e-commerce.

In future research, the study will focus on the empirical study based on the proposed conceptual model, and prove whether the related hypotheses can be supported. In the next stage, the research will collect around 250 surveys from Chinese 3PL providers, and the professional logistics institution has agreed to assist the data collection because its members have at least 3 years of practical work experience in related to the logistics industry for the international business. The structural equation modeling will be employed for the data analysis based on the research conceptual model, deeply analyzing the factors influencing the responsiveness of 3PL providers and find other potential variables.

\section{References}

1. G. Gereffi, J. Lee,Why the world suddenly cares about Global Value Chains?, Journal of Supply Chain Management. 48 (2012) 24-32.

2. $P$. Antràs, D. Chor, Organizing the Global Value Chain, Journal of The Econometric Society. 81 (2013) 2127-2204.

3. M. P. Timmer, A. A. Erumban, B.t Los, R. Stehrer, G. J. d. Vries, Slicing up Global Value Chains, The Journal of Economic Perspective. 28 (2014) 99-118.

4. D. Jothimani, and S. P. Sarmah, Supply chain performance measurement for third party logistics, Benchmarking: An International Journal 21 (2014) 944-963.

5. M. Falk, E. Hagsten, E-commerce trends and impacts across Europe, International Journal of Production Ecomics. 170 (2015) 357-369.

6. G. Herrera et al., The drivers and impediments for cross-border e-commerce in the EU, Information Economics and Policy. 28 (2014) 83-96.

7. W. K. Tan, Albert et al. State of third party logistics providers in China, Industrial Management \& Data Systems. 114 (2014) 1322-1343.

8. E.Rabinovich, A. M. Knemeyer and C. M. Mayer, Why do Internet commerce firms incorporate logistics service providers in their distribution channels?, Journal of Operations Management. 25 (2007) 661-681.

9. $\quad$. Terzi, The impact of e-commerce on international trade and employment, ProcediaSocial and Behavioral Sciences. 24 (2011) 745-753. 
10. R. M. Bosire, et al. The Impact of Outsourcing on Lead-Time and Customer Service in Supermarkets in Nairobi-Kenya, European Journal of Business and Management. ISSN (2013) 2222-1905.

11.S. Sluis,P.D. Giovanni, The selection of contracts in supply chain_an empirical analysis, Journal of Operations Management. 41 (2016) 1-11.

12. J. S. Raue, and C. M. Wallenburg, Alike or not? Partner similarity and its outcome in horizontal cooperations between logistics service providers. Logistics Research. 6 (2013) 217-230.

13. K. Luo, E-Commerce Laws and Practices in China, Ariz. J. Int'l \& Comp. L. 33 (2016) 219. 